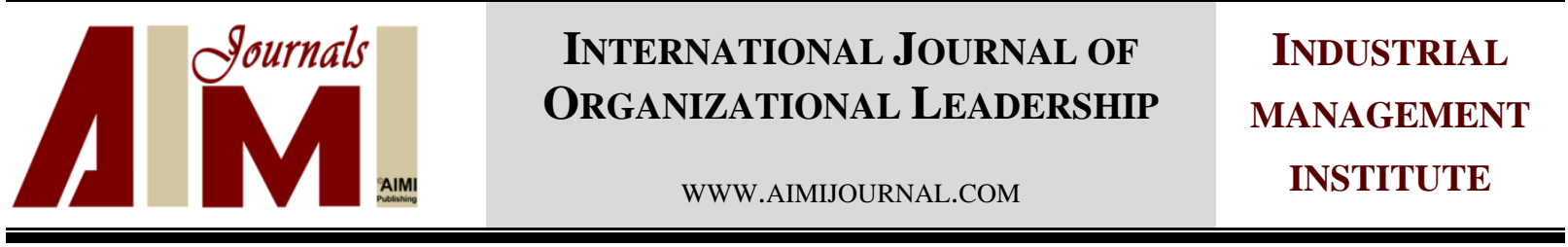

\title{
An analysis of the relationship between managers' ethical leadership style with teachers' organizational commitment and job burnout
}

\author{
Fatemeh Eslamieh ${ }^{1}$, Amir Hossein Mohammad Davoudi ${ }^{2}$ \\ ${ }^{1}$ Young Researchers and Elite Club, Garmsar Branch, Islamic Azad University, Garmsar, Iran \\ ${ }^{2}$ Department of Education Administration, College of Human Science, Saveh Branch, Islamic Azad University, \\ Saveh, Iran
}

\begin{abstract}
Keywords:

Ethical leadership,

Organizational

Commitment, Job Burnout

The present research was conducted with the aim of exposition of the relationship between managers' ethical leadership style with teachers' organizational commitment and burnout. The study was an applied and descriptive research. Statistical population included all teachers of guidance school in district four of Tehran which amounted 744 teachers of which 260 teachers (males=177 and females $=83$ ) were selected based on Morgan's table.

Received

09 May 2016

Received in revised form 01 August 2016

Accepted

18 August 2016

Correspondence:

adavoudi838@yahoo.com

Sampling method was stratified random sampling based on their gender. For collecting data, three questionnaires, namely job burnout (Maslach \& Jackson,1981), organizational commitment (Allen \& Mayer, 1990), and ethical leadership which was developed by the researchers came into use. Reliability of the three questionnaires were acceptable and for analyzing the obtained data, the statistical methods of Kolmogorov-Smirnov test, Pearson correlation coefficient, and regression were used. The results showed that the managers' ethical leadership style had a positive relationship with the teachers' organizational commitment and a negative relationship with their burnout. Following this, the results of regression analysis indicated that 64.1 percent of the changes in teachers' organizational commitment and 48.3 percent of the changes in their burnout could be explained by the managers' ethical leadership style.
\end{abstract}

(C)AIMI Journals

\section{Introduction}

The concepts that have recently attracted the attention of industrial and organizational psychologists involve the fatigue, burnout, lethargy, and sluggishness of employees technically referred to as burnout. It seems that it is a kind of response or reaction to the stressful 
conditions in the working environment which leads to some changes in the individual's attitude and behavior (Saatchi, 2000). The notion of burnout was proposed by Herbert Freudenberger who had a job as a psychoanalyst in a clinic in NewYork (Shepherd, Tashchian, \& Ridnour, 2011). However the most widely accepted and used definition of burnout was made by Maslach who described it as a multidimensional structure. Burnout emerges as a result of the efforts to cope with the stress arising from occupation. Job burnout is influenced by different factors such as the type of job, conflicts, role confusion, excessive work pressure, management, lack of social support, organizational changes, and working hours (Fletcher, 2001). In appropriate working conditions, feeling of organizational inefficiency, lack of individual progress, few chances of promotion, rigid and restricting rules, and regulations in the organizational system are among other factors that influence and increase job burnout (Alavi, 2003). It is more likely that the employees experiencing burnout in the early stages of their career will quit their job. The employees who do not quit their job will be those who know how to cope with burnout. The issue of job burnout was emphasized by Maslach and Jackson (1981) in California after it was first focused on by Freudenberger.

Maslach and Jackson (1981) presented an experimental view of the analysis of job burnout. They developed the first job burnout questionnaire based on three criteria which are touched upon briefly below.

Analysis of Emotional Fatigue: This refers to the feelings in which the individual has lost his/her emotional forces and is not able to establish an emotional relationship with others.

Depersonalization (Negative Attitude in Response to Others): This alludes to the unemotional, irrelevant, and fierce responses and reactions to the service-receivers (customers) and colleagues and is accompanied by fatigue, negative emotions, and attitudes along with a reproaching spirit.

Feeling of Self-Efficacy (Lack of Individual Success): This refers to the feeling of selfefficacy and successful progress when working with others.

Maslach and Jackson (1981) believe that the individual has a feeling of emotional fatigue first, then depersonalization, and finally a feeling of lack of individual success. In this model, emotional fatigue has been considered as the most important burnout component. Emotional fatigue is directly related to the higher levels of job application because it is a reflection of the contrast between individual and organizational demands which puts pressure on the employees. For instance, work pressure is considered as an important index of emotional fatigue. Individuals who do not have enough time for work may have to spend a high emotional energy to be successful in that job and in this case, they are led to emotional fatigue. High and longterm emotional face-to-face interactions can also lead to emotional fatigue. Therefore, job burnout is more likely to happen in occupational groups in which there are interactional relationships and contacts. Burnout may have many negative effects both on organization and individual. Cynicism, job dissatisfaction, low organizational commitment, and quitting the job are among the most important impacts on organization (Ghorpade, Lackritz, \& Singh, 2007).

Teachers are among the groups which have been examined in terms of job burnout as an undesirable experience because teaching and instruction has been defined as a challenging profession. Statistical reports show that the number of teachers who quit their jobs tends to 
increase. The results of the studies indicate that the main reason of this is job burnout and this problem has caused a great and disastrous damage to the investments and led to wasting of the academic talents (Jackson, Schwab, \& Schuler, 1986); Tomic, Evers, \& Brouwers, 2004).

In an investigation in America it was estimated that about 5 to 20 percent of the teachers have job burnout. In another investigation in Hong Kong, it was reported that guidance school teachers' level of job burnout was 45 percent. The investigations made in Iran also showed that there are levels of job burnout. For instance, in a study on 1068 teachers and education officials and employees in Kerman, 675 of the elementary school teachers were found to have job burnout. In another study on elementary school teachers in Fars, it was found that only three of the teachers (4.4 percent) do not have job burnout and others have this problem either at low or high levels (65.8\% low, 5.26\% mild, and 3.3\% high). Some researchers (e.g., Nabavian, 2011) have confirmed the existence of job burnout among 69 percent of the Iranian teachers. Based on the results of these studies, the teachers who suffer job burnout are emotionally tired and have a low motivation for work; therefore, their energy and excitement for work is very low (Spector \& Fox, 2002).

Organizational commitment or faithfulness is also one of the most important concerns of the managers. It is a multi-dimensional concept that has some positive consequences such as absence and movement, citizenship behavior, work effort, and improved occupational performance (Riketta \& Dick, 2005). According to Allen and Mayer (1990), organizational commitment refers to individuals' positive or negative attitudes towards the organization (not the job) in which they are working. They believe there are three types of organizational commitment, namely emotional commitment, continuous commitment, and normative commitment. Emotional commitment refers to the employees' emotional dependence and their feeling of identity and involvement in the organization; in this form of commitment the employees stay in the organization because they want to stay. Following this, continuous commitment refers to the costs of leaving the organization. The employees' willingness to stay in the organization is indicative of the fact that they need their job and cannot do any other job. Accordingly, the employees stay in the organization because they need to stay. In addition, normative commitment alludes to the employees' commitment to continue working in an organization due to the pressure exerted on them by others. The employees stay in the organization because they feel they have to stay (Luthans, 2008).

The results of the studies demonstrated that organizational commitment has a key and pivotal role in the promotion, preserving, and performance of the work force (Conger, 1989; Doherty \& Dunylchuk, 1996). In fact, work force can be efficient and effective only if it is motivated and has high professional satisfaction and commitment (Norouzi, 2009). Robinson, Porporino, and Simourad (1992) suggested that the employees who have a high emotional commitment are happier with their job, spend less time with jobs irrelevant to their work, and are less likely to leave their job. All of these are highly dependent on the leadership style of the organization manager as a person who is responsible for leading and guiding the organization.

Considering the key and pivotal role of managers in directing the organization towards achieving its goals and ensuring its organizational survival, there is a need for coordination and a direct interaction at all levels of the organization with the leaders for this purpose. Therefore, 
leaders attempt to prepare the ground for individual, group, and organizational development and individuals' faithfulness to the organization. The leaders' attempt to create a sense of organizational unity and agreement and focus on their pioneering role in development and advancement by preparing the ground for the appearance of the concept of ethical leadership. Ethical leadership starts with the understanding and assumptions that the leaders have about their surrounding world (Rezvanpour, 2008).

Ethical leadership has been explained as presenting the manifestation of normatively proper conduct by personal actions and interpersonal relationships, and the development of such conduct to followers through two-way communication, reinforcement, and decision-making (Brown, Treviño, \& Harrison, 2005). It often seems that ethical leadership should be in the form of soft and calm leadership and there should be nothing but the reality. Being an ethical leadership means using one's authority in the right way in any situation. Sometimes the conditions require leadership to be kind. Instead, rigid and harsh leadership cannot last a long time without anger and pessimism (Rezvanpour, 2008). Ethical leaders express to employees that performing works in the right way is expected, encouraged and valued; in turn employees are inclined to apprehend an ethical organizational environment (Mayer, Kuenzi, \& Greenbaum, 2010). Ethical leaders communicate with their subordinates about their ethical and values-based expectations and use reward and punishment to encourage ethical conduct or prevent unethical behaviors (Treviño, Hartman, \& Brown, 2000).

According to Khuntia and Suar (2004), any organization has short and long-term goals. Achieving these goals is not possible without effective leadership and management. Supervisors and managers can strengthen or weaken commitment, satisfaction, performance and ethical behavior of the employees with the measures they take and with their actions. In fact, based on the definitions made of leadership leaders are dependent more on their individual abilities and forces (mental and social) than their position and status as the leader. Ethical leadership came into existence influenced by these emphases on presenting theories and the existing research studies (Golparvar \& Nayyeri, 2010).

Ethical leaders consistently attempt to take into consideration the accepted humanitarian and moral standards and principles in their beliefs and the values and behaviors in the working environment. These leaders have a high commitment and sense of responsibility for their highlevel goals; in addition they are foresighted and wise, show pride in the right way and situation, are patient and tolerant, emphasize moral principles underscored in desirable work relationships, and are hard-working, resistant, and persistent (Khuntia \& Suar, 2004). Other researchers also consider honesty, determination, flexibility, righteousness, tractability, modesty, and they show the feelings in the right situation, audacity, and feeling of responsibility as other characteristics of the ethical leaders (Solomon, 1999; Guillen \& Gonzalez, 2001).

\section{The Literature Review}

Many studies have been conducted relating to the research variables of the study. Each has approached the issue from a different perspective and yielded different results. Eslamieh \& Darabeigy (2015) conducted a study and examined the relationship between organizational 
citizenship behavior, organizational commitment, and organizational trust. The results revealed that there is a significant relationship between organizational citizenship behaviour, organizational commitment, and organizational trust. Also, 66.8 changes of organizational commitment as 54.3 changes of organizational trust is predictable through the components of organizational citizenship. Sharifi and Eslamieh (2011) confirmed the existence of a meaningful relationship between these two variables. Seyyedi and Izadi (2010) examined the relationship between managers' leadership style and commitment of the police staff in Fars, Iran. Based on the estimated correction coefficients, using magisterial and benevolent leadership style, managers had a weak but meaningful relationship with their consultative and cooperative leadership style and also with the organizational commitment of the employees under study. Bakhshi Soureshjani (2010) examined the relationship of emotional intelligence and mental health with job burnout in teachers, nurses, and employees of Water and Power Authority. The results were indicative of a negative meaningful relationship between these three variables.

Emadifar (2009) sought the views of university staff about the managers' leadership styles and examined the relationship between these styles and the employees' empowerment. He found that there was a positive meaningful relationship between the ethical leadership style score and empowerment of the employees. Siu and Lam (2009) conducted a comparative study of the managers and non-managers' ethical understandings in Hong Kong. They compared the ethical understandings of managers and non-managers in their study and concluded that managers have a higher level of ethical behavior and act more ethically compared to those who hold other jobs. Furthermore, managers are willing to transmit their views which are more based on the ethics to others. In addition, the ability to accept unethical behavior considering the income is decreased and the employees of the non-profit organizations observe and care about the ethical standards more.

Okpara and Wynn (2008) analyzed the influence of ethical atmosphere on the job satisfaction and organizational commitment of Nigerian managers and identified the unethical activities among these managers. The results obtained were indicative of a positive meaningful relationship between the ethical atmosphere and organizational commitment. Berry (2008) conducted another study entitled "Correlation between leadership, organizational climate, and organizational commitment". The findings of this study showed that leadership behavior of the supervisors had an influence on the organizational commitment and the organizational atmosphere of the employees. In their study on hospital nurses in Sydney, Lok, Westwood, and Crawford (2005) found that interactive leadership style had a highly meaningful relationship with the organizational commitment of the employees.

\section{Research Questions}

Based on the literature and the theoretical background (see Figure 1), the present study attempts to examine the relationship between managers' ethical leadership style and teachers' organizational commitment and job burnout. Accordingly, the following research questions guided the study:

1. Is there any relationship between managers' ethical leadership style and teachers' organizational commitment? 
2. Is there any relationship between managers' ethical leadership style and teachers' job burnout?

3. To what extent can managers' ethical leadership style predict teachers' organizational commitment and job burnout?

Figure 1 displays the conceptual framework of the study.

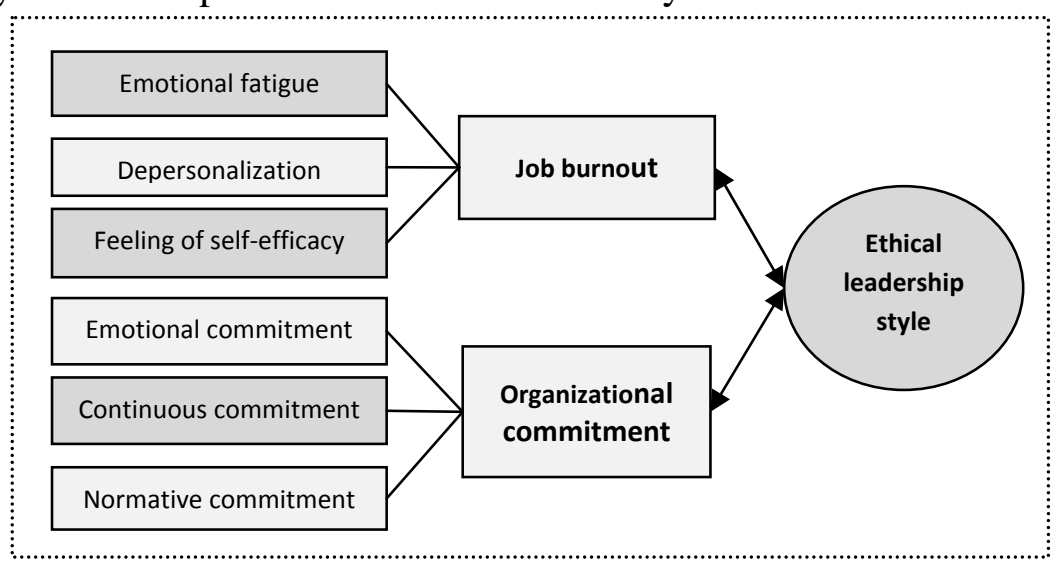

Figure 1. The conceptual framework of the study

\section{Method}

The present study is applied, descriptive, and correlational in terms of purpose. The target population of the study are all the male and female secondary school teachers in district four of Tehran including 774 (529 female and 245 male) teachers. The sample size was determined using Krejcie and Morgan's table and estimated to be 260 teachers. The samples were selected from the target population using stratified random sampling method based on their gender (see Table 1).

Table 1 shows the distribution of the population and samples based on gender.

Table 1

Distribution of the Population and Samples based on Gender

\begin{tabular}{lccc}
\hline Gender & Target Population & Sample Size & Percent \\
\hline Female Employees & 529 & 177 & 68.3 \\
Male Employees & 245 & 83 & 31.7 \\
Total & 774 & 260 & 100 \\
\hline
\end{tabular}

Three questionnaire were used for data collection in the present study, namely Maslach burnout inventory, organizational commitment questionnaire, and ethical leadership style questionnaire.

Maslach Burnout Inventory: This questionnaire developed by Maslach and Jackson (1981) was used to measure the level of job burnout among the population under the study. It is known as a standard instrument for measuring three independent aspects of job burnout and includes 22 separate items about the feelings and attitudes that measure job burnout syndrome from different perspectives. In this instrument, nine items are related to emotional fatigue, five of them concern depersonalization, and eight items relate to the feeling of self-efficacy. Scoring is based on a 7-point Likert scale with the answers ranging from "never" to "every day" with the (0) showing the lowest score and (6) indicating the highest. The Internal validity of emotional fatigue, depersonalization and of self-efficacy were $0.90,0.70$ and 0.79 , respectively by 
Maslach and Jackson. The reliability and validity of this questionnaire have been confirmed by Australian researchers in 2002 (Yaman and Soler, 2002). Also, in Iran the reliability and validity of this questionnaire has confirmed and reported 0.78 by the "Filiyan" For the first time (Taleyee, Mokhber, Mohammad-Nejad, \& Samari, 2008).

Organizational Commitment Questionnaire: This questionnaire developed by Allen and Mayer (1990) has three dimensions including emotional, continuous, and normative commitment. It is a 21-item questionnaire with a four-point Likert scale, with answers "strongly disagree”, “disagree”, “agree”, and "strongly agree”. The reliability of affective commitment, normative commitment, and continued commitment were 0.82, 0.73, and 0.76, respectively which were confirmed by Allen and Mayer. Besides, the total validity of the questionnaire has confirmed and reported 0.85 by Eslamieh and Darabeigy (2015) and 0.91 by Seyyedi and Izadi (2010).

Ethical Leadership Style Questionnaire: This questionnaire was developed by the researchers. By reviewing the theoretical background and the literature, a 11-item five-point Likert scale questionnaire was developed with the answers "totally disagree”, “disagree”, "no idea", "agree", and "totally agree". Accordingly, 1 represents the lowest and 5 shows the highest score. To determine the validity of the content, diagnostic (convergence and divergence) has been used. All features of the research measures, face and content validity of the questionnaire was approved. The diagnostic validity (convergent and divergent), is presented by Smart-PLS statistical software and is represented in Table 2. To verify the convergent validity of the variables, the average variance extracted (AVE) was used. The value of AVE should be greater than 0.50 in order to achieve convergent validity. In an AVE analysis, we test to see if the square root of every AVE value belonging to each latent construct is much larger than any correlation among any pair of latent constructs; AVE measures the explained variance of the construct. To measure the reliability, the first sample including 30 questionnaires were pre-tested, then the reliability was determined by Cronbach's alpha using the data obtained from the questionnaires and using SPSS software; the Cronbach Alpha value is greater than 0.70 so reliability was achieved.

The collected data from questionnaires were analyzed using K-S, AVE, Pearson's correlation and regression on the SPSS and PLS software. Table 2 displays the results of diagnostic reliability and validity coefficients (convergent and divergent) questionnaires.

Table 2

Results of Diagnostic Reliability and Validity Coefficients (Convergent and Divergent) Questionnaires

\begin{tabular}{|c|c|c|c|c|c|c|}
\hline \multirow[b]{3}{*}{ Variable } & \multicolumn{4}{|c|}{ Diagnostic Validity } & \multirow[b]{3}{*}{ Reliability } & \multirow[b]{3}{*}{$\begin{array}{c}\text { Estimated } \\
\text { Results } \\
\end{array}$} \\
\hline & \multirow[b]{2}{*}{$\begin{array}{c}\text { Convergent } \\
\text { Validity } \\
\end{array}$} & \multicolumn{3}{|c|}{ Divergent Validity } & & \\
\hline & & Job Burnout & $\begin{array}{c}\text { Organizational } \\
\text { Commitment }\end{array}$ & $\begin{array}{c}\text { Ethical } \\
\text { Leadership }\end{array}$ & & \\
\hline Job Burnout & 0.61 & 0.78 & & & 0.82 & Accepted \\
\hline $\begin{array}{c}\text { Organizational } \\
\text { Commitment }\end{array}$ & 0.60 & 0.67 & 0.77 & & 0.83 & Accepted \\
\hline $\begin{array}{c}\text { Ethical } \\
\text { Leadership Style }\end{array}$ & 0.65 & 0.61 & 0.67 & 0.80 & 0.79 & Accepted \\
\hline
\end{tabular}




\section{Results}

\section{Statistical Tests for Normality Distribution}

Assessing the normality assumption should be taken into account for taking advantage of parametric statistical tests. Statistical tests for normality was Kolmogorov-Smirnov test which was provided by the SPSS software. Significant level were greater than 0.05 . Therefore, variables followed normal features. Table 3 shows the results of K-S.

Table 3

Results of K-S

\begin{tabular}{lll}
\hline & K-S & Sig. \\
\hline Job Burnout & 2.35 & 0.22 \\
Organizational Commitment & 2.71 & 0.11 \\
Ethical Leadership Style & 3.30 & 0.21 \\
\hline
\end{tabular}

Q1: Is there any relationship between managers' ethical leadership style and teachers' organizational commitment?

The coefficients of correlation between managers' ethical leadership and teachers' organizational commitment are presented in Table 4. Regarding Table 4, the estimated levels of significance are all lower than 0.05 confirming the existence of a positive meaningful relationship between these two variables.

Table 4

Coefficients of Pearson Correlation between Managers' Ethical Leadership and Teachers' Organizational Commitment

\begin{tabular}{lcc}
\hline Component & Indices & Ethical Leadership Style \\
\hline Emotional Commitment & Pearson Correlation & $0.64^{88}$ \\
& Sig. & 0.00 \\
Continuous Commitment & Pearson Correlation & $0.50^{88}$ \\
& Sig. & 0.00 \\
Normative Commitment & Pearson Correlation & $0.19^{88}$ \\
& Sig. & 0.00 \\
\hline
\end{tabular}

Q2. Is there any relationship between managers' ethical leadership style and teachers' job burnout?

As it is shown in Table 5, the coefficients of correlation between managers' ethical leadership style and teachers' job burnout are all lower than 0.05 and meaningful indicating that there exist a negative meaningful relationship between the managers' ethical leadership style and teachers' job burnout.

Table 5

Coefficients of Pearson Correlation between Managers' Ethical Leadership and Teachers’ Job Burnout

\begin{tabular}{ccc}
\hline Component & Indices & Ethical Leadership Style \\
\hline Emotional Fatigue & Pearson Correlation & $-0.23^{88}$ \\
& Sig. & 0.00 \\
Depersonalization & Pearson Correlation & $-0.43^{88}$ \\
& Sig. & 0.00 \\
Feeling of Self-Efficiency & Pearson Correlation & $-0.65^{88}$ \\
& Sig. & 0.00 \\
\hline
\end{tabular}


Q3. To what extent can managers' ethical leadership style predict teachers' organizational commitment and job burnout?

According to Table 6, the corrected coefficients is 0.641 for organizational commitment and 0.483 for job burnout. These values show that 64.1 percent of the changes in teachers' organizational commitment and 48.3 percent of the changes in their job burnout is explained by managers' ethical leadership style.

Table 6

A Summary of the Regression Model between Managers' Ethical Leadership Style and Teachers' Organizational Commitment and Job Burnout

\begin{tabular}{ccccc}
\hline Model & $\mathrm{R}$ & $\mathrm{R} 2$ & Corrected Coefficient & Estimation Error \\
\hline Organizational Commitment & 0.80 & 0.64 & 0.64 & 0.39 \\
Job Burnout & 0.69 & 0.48 & 0.48 & 0.53 \\
\hline
\end{tabular}

Based on Table 7, the F values calculated for organizational commitment is 463 and 242 for job burnout with the df of 259 which is higher than the critical F values (3.84). Therefore, it can be concluded at 0.95 level of confidence that there is a meaningful relationship between variables of the study (ethical leadership style, organizational commitment, and job burnout) and this relationship is not accidental.

Table 7

F-Test for the Linear Relationship between the Components of Ethical Leadership Style, Organizational Commitment, and Job Burnout

\begin{tabular}{|c|c|c|c|c|c|c|}
\hline Model & & Total Squares & df & Mean Square & $\mathrm{F}$ & Sig. \\
\hline \multirow[t]{3}{*}{ Organizational Commitment } & Regression & 70.85 & 1 & 70.85 & & \\
\hline & Residues & 39.44 & 258 & 0.153 & 463 & 0.00 \\
\hline & Total & 110.30 & 259 & & & \\
\hline \multirow[t]{3}{*}{ Job Burnout } & Regression & 69.78 & 1 & 69.78 & & \\
\hline & Residues & 74.18 & 258 & 0.28 & 242 & 0.00 \\
\hline & Total & 143.97 & 259 & & & \\
\hline
\end{tabular}

As it is depicted in Table 8, the Beta coefficients show that the contribution of the ethical leadership style to teachers' organizational commitment is 0.801 and to their job burnout it is 0.696.

Table 8

The Results of Multivariate Regression

\begin{tabular}{|c|c|c|c|c|c|c|c|}
\hline \multicolumn{5}{|c|}{ Organizational Commitment } & \multicolumn{3}{|c|}{ Job Burnout } \\
\hline Model & Beta & $\mathrm{t}$ & Sig. & Model & Beta & $\mathrm{t}$ & Sig. \\
\hline (Fixed) & & 15.4 & 0.00 & (Fixed) & & 8.9 & 0.00 \\
\hline $\begin{array}{c}\text { Ethical } \\
\text { Leadership }\end{array}$ & 0.80 & 21.5 & 0.00 & $\begin{array}{c}\text { Ethical } \\
\text { Leadership }\end{array}$ & 0.69 & 15.5 & 0.00 \\
\hline
\end{tabular}

\section{Conclusion}

The relationship between man and work has always attracted the attention of philosophers. Men spend a major part of their life at work. Work is considered as the social reality and social expectation to which men seem to confirm. Employees are among the most important determinants and leading factors that determine the success of an organization in a competitive 
environment. Analyzing the relationship between managers' ethical leadership style and organizational commitment and job burnout is particularly crucial nowadays.

Basically, in the present competing world, the committed, highly motivated, and skillful human resources play a strategic and important role in the success of their organizations. Based on the results, there is a positive meaningful relationship between managers' ethical leadership style and teachers' organizational commitment. Following this, 64.1 percent of the changes in teachers' commitment could be explained by the managers' ethical leadership. This result is consistent with and supported by the findings of Berry (2008), Emadifar (2009), Eslamieh and Darabeigy (2015), Lok et al. (2005), Okpara and Wynn (2008), and Siu and Lam (2009).

Managers as the official representatives of the organizations have the most prominent role in coordination and increasing productivity of the organizations. Organizations' success in improving its productivity and achieving its goals is dependent on their effective management and implementation of appropriate leadership styles. Using the right leadership style can improve job satisfaction, employees' organizational commitment, and consequently productivity of the organization (Lambert \& Nugent, 1999). In any work, management and leadership require observing the ethical aspects and issues (Sanjari, 1996). Leaders can reach the pinnacle of power in organizations and use their capabilities by valuing and respecting human integrity (Hazer, 1992). According to Isbell (2006), when employees feel that the activities of their leaders are unethical, their performance, productivity, work conscience, and job satisfaction decreases to a large extent. Therefore, leaders especial in educational organizations should have high ethical standards so that the employees feel their behavior is ethical. The findings further showed that there was a negative meaningful relationship between managers ethical leadership style and teachers' job burnout; to this end, 48.3 percent of the changes in teachers' job burnout was explained by the managers' ethical leadership. The study by Bakhshi Soureshjani (2010) was in line with the present study.

Teachers are among the groups who are more exposed to job burnout and one of the influential factors leading to an increase in the level of their burnout is the school managers' behaviour and leadership style. Leadership style influences the efficiency and job satisfaction of the employees and it also affects the attitudes, beliefs, and mental and organizational health at schools. Handrickson (1999) defines teachers' job burnout as physical, emotional and feedback exhaustion followed by a feeling of unhappiness and solemnity in a way that the feeling of teaching joy diminishes gradually and the instructions lose their effectiveness. According to researchers, job burnout especially of teachers is contagious and corrupts the educational system via job dissatisfaction and negativism and is spread like a malignant disease until it destroys the whole educational system (Dworkin, Saha, \& Hill, 2003). The results of a study by Egyed and Short (2006) confirm this fact; they found that teachers who have high job burnout acted less sure about sending their students for Special Educational Tests compared to other teachers.

Pressure from the managers and leaders is one of the major causes of the employees' job burnout in a way that from among the factors leading to job burnout, most of the studies are mainly focused on the pressures in the working environment, job and management policies, and emphasize preventing job burnout and increasing efficiency. 
The education system should lay the foundation for all the activities and major social issues and ensure the persistence, viability, and development. In line with this, the managers and leaders of this system as the advancers, directors, and coordinators of these activities are very important. Managers of this system should try to decrease and eliminate the pressures upon those working for the system as much as they can to prepare the ground for the satisfaction, faithfulness, and commitment of the employees and increase their productivity. For this purpose, managers are recommended to strengthen and improve their leadership role based on the ethics to improve the boring and undesirable organizational atmosphere and in this way eliminate the factors that lead to a decrease in organizational commitment and employees' burnout.

The sources, and instigators of tension and mental pressure on the teachers should be identified and in order to decrease and eliminate these factors, rewarding and encouraging policies should be followed and training session should be held to increase their knowledge and improve their personal performance (teachers' views should be sought for holding the training sessions). In addition, appropriate conditions should be provided for teachers' freedom of action and professional independence to prepare the ground for the formation of discussions and exchange of ideas related to the professional duties of the managers and teachers. Besides, a social assistance and advice section should be established in schools to decrease teachers' job burnout and identify their problems and difficulties. Assistants and advisors reflect the existing situation and present solutions to the teachers' problems by analyzing and evaluating the existing situation or by participating in the sessions held by the school managers and deputies. The importance of the topic of the present study is recognized all over the world. Researchers can use this study as a guide for doing research in different parts of the world and help to solve the related problems.

\section{References}

Allen, N. J., \& Meyer, J. P. (1990). The measurement and antecedents of affective, continuance, and normative commitment to the organization. Journal of Occupational Psychology, 63, 1-18.

Alavi, S. A. (1992). Psychology of management and organizations (organizational behavior) (1 ${ }^{\text {st }}$ ed.). Tehran: State Management Education Center.

Bakhshi Soureshjani, L. (2010). The relationship between emotional intelligence and mental health with job burnout in teachers, nurses, and staff of Water and Power Authority in Behbahan, Iran. Journal of Learning Management Innovation (New Ideas in education), 6, 37-58.

Berry, J. R. (2008). The relationships among leadership practices, organizational climate, and organizational commitment within church ministry settings. (Unpublished Doctoral dissertation). Regent University, Virginia.

Blase, J., Dedrick, C., \& Strathe, M. (1986). Leadership behaviour of school principals in relation to teacher stress, satisfaction and performance. The Journal of Humanistic Education \& Development, 24(4), 159-171.

Brown, M. E., Treviño, L. K., \& Harrison, D. A. (2005). Ethical leadership: A social learning perspective for construct development and testing. Organizational Behaviour and Human Decision Processes, 97(2), 117-134.

Conger, J. A. (1989). Leadership: The art of empowering others. The Academy of Management Executive, 3(1), 17-24.

Doherty A. J., \& Danylchuk, K. E. (1996). Transformational and transactional leadership in interuniversity athletics management. Journal of Sport Management, 10(3), 292-309.

Dworkin, A. G., Saha, L. J., \& Hill, A. N. (2003). Teacher burnout and perceptions of a democratic school environment. International Education Journal, 4(2),13-22. 
Eslamieh, F., \& Darabeigy, M. (2015). The rule of organizational behaviour at the university and its relationship with organizational commitment and trust (Case Study: Iran University of Medical Sciences). Proceedings of the National Conference on the Modern Management of Science, Gorgan.

Emadifar, A. (2009). Analysis of managers' ethical leadership from the perspective of the employees of the University of Ferdousi and its relationship with their empowerment (Unpublished master's thesis) University of Ferdousi, Mashhad, Iran.

Egyed, C. J., \& Short, R. J. (2006). Teacher self-efficacy, burnout, experience and decision to refer a disruptive student. School Psychology International, 27(4), 462-474.

Fletcher, C. E. (2001). Hospital RN's job satisfactions and dissatisfactions. Journal of Nursing Administration, 31(6), 324-331.

Ghorpade, J., Lackritz, J., \& Singh, G. (2007). Burnout and personality: Evidence from academia. Journal of Career Assessment, 15(2), 240-256.

Golparvar, M., \& Nayyeri, S. (2010). The relationship between organizational and ethical values and moral-based leadership with stress and burnout of the employees of Steel Industry Company. Occupational \& Organizational Counseling, 2(5), 7192.

Guillen, M., \& Gonzalez, T. F. (2001). The ethical dimension of managerial leadership: Two illustrative case studies in T \& M. Journal of Business Ethics, 34(3/4), 175-189.

Hazer, M. (1992). Ethical aspects of leadership in organizations. Journal of Public Management, 16, 45-48.

Handrickson, J. (1999). Gender-related differences in burnout. Available: www.Findarticle.com

Isbell, J. (2006). Perceptions concerning the ethical leadership of community college deans and directors and the impact of those perceptions on job satisfaction and work performance (Doctoral dissertation). Capella University, Minneapolis.

Khuntia, R., \& Suar, D. (2004). A scale to assess ethical leadership of Indian private and public sector managers. Journal of Business Ethics, 49,13-26.

Lambert V. A., \& Nugent, K. E. (1999). Leadership style for facilitating the integration of culturally appropriate health care. Seminars for Nurse Managers, 7(4), 172-178.

Lok, P. Westwood, R., \& Crawford, J. (2005). Perceptions of organizational subculture and their significance for organizational commitment. Applied Psychology: An International Review, 54(4), 490-514.

Luthans, F. (2008). Organizational behaviour. Boston: McGraw Hill.

Maslach, C., \& Jackson, S. E. (1981). The measurement of experienced burnout. Journal of Occupational Behaviour, 2, 99113.

Mayer, D. M., Kuenzi, M., \& Greenbaum, R. L. (2010). Examining the link between ethical leadership and employee misconduct: The mediating role of ethical climate. Journal of Business Ethics, 95, 7-16.

Nabavian, M. (2011). Job Burnout. Shiraz: Gol.

Norouzi, F. (2009). The level of commitment of the employees of Islamic Azad University, Tehran Shomal Branch and University of Shahid Beheshti and the factors affecting it. Journal of Sociology, 3, 143-167.

Okpara, J. O., Wynn, p. (2008). The impact of ethical climate on job satisfaction and commitment in Nigeria: Implications for management development. Journal of Management Development, 9(27), 935-950.

Rezvanpour, M. (2008). The role of leadership in organizational integrity and five ethical leadership styles. The Journal of Car Industry, 119, 21-23.

Riketta , M., \& Van Dick, R. (2005). Foci of attachment in organizations: A meta/analytic comparison of the strength and correlates of work group versus organizational identification and commitment. Journal of Vocational Behavior, 67(3), 490510.

Robinson, D., Porporino, F. J., \& Simourd, L. (1992). Staff commitment in the correctional service of Canada. Ottawa: Research \& Statistic Branch.

Sa'atchi, M. (2008). Mental health in the workplace with emphasis on stress and burnout. Tehran: Viraiesh.

Sanjari, A. R. (1996). The art of management and ethical leadership in educational organizations. Tadbir Journal, 69, $28-31$.

Seyyedi, S. M., \& Izadi, A. (2010). An investigation of the relationship managers' leadership styles and the organizational commitment of the Police staff in Fars, Iran. Knowledge of Law Enforcement Journal, 12(1), 107-142.

Sharifi, A., \& Eslamieh, F. (2011). An analysis of the relationship between the type of organizational structure (bureaucratic and professional) and ethicality of the school managers in the east of Tehran, Iran. Proceedings of the National Conference on Educational Management in Theory and Practice, Tehran, Iran. 
Shepherd, D. C., Tashchian, A., \& Ridnour, E. R. (2011). An investigation of the job burnout syndrome in personal selling. Journal of Personal Selling \& Sales Management, 31(4),397-409.

Siu, N. Y., \& Lam, K. J. (2009). A comparative study of ethical perceptions of managers and non-managers. Journal of Business Ethics, 88, 167-183.

Solomon, R. (1999). A better way to think about business: How personal integrity leads to corporate success. New York, NY: Oxford University Press.

Spector, E. P., Fox, S. (2002). An emotion/cantered model of voluntary work behaviour, some parallels between counterproductive work behaviour and organizational citizenship behaviour. Human Resource Management Review, 12, 269-292.

Taleyee, A., Mokhber, N., Mohammad-Nejad, M., \& Samari A. A. (2008). Burnout and its related factors in staff of university hospitals in Mashhad in 2006. Koomesh, 9(3), 237-246.

Tomic, W., Evers, W. J. G., \& Brouwers, A. (2004). Existential fulfilment and teacher burnout. European Psychotherapy, 5(1), 65-73.

Treviño, L. K., Hartman, L. P., \& Brown, M. (2004). Moral person and moral manager: How executives develop a reputation for ethical leadership. California Management Review, 42,128-142.

Yaman, H., Soler, J. K. (2000). The job related burnout questionnaire: A multinational pilot study in family practice. Australian Family Physician, 31(11), 1055-1056. 